\title{
Otitis media pathogens - A life entrapped in biofilm communities
}

\author{
Maria Daniela Silva (D) and Sanna Sillankorva* (ID \\ CEB - Centre of Biological Engineering, LIBRO - Laboratório de Investigação em Biofilmes Rosário Oliveira, University of Minho, \\ Braga, Portugal
}

ABSTRACT

Otitis media is a group of inflammatory diseases of the middle ear with great impact on children worldwide. The most common reported bacterial pathogens are Streptococcus pneumoniae, Haemophilus influenzae and Moraxella catarrhalis. Over the last years, the role of biofilms formed by otopathogens that contribute to otitis media recurrence and chronicity has been established. An improved understanding of the properties of biofilms formed by these bacteria, which factors influence them, and how these affect the host inflammatory response is important for the development of novel strategies for the treatment of otitis media. This review focuses on the biofilm nature that the most prevalent otopathogens adopt in otitis media infections. In addition, new treatment approaches targeting biofilms are highlighted.
ARTICLE HISTORY

Received 23 April 2019

Revised 31 July 2019

Accepted 22 August 2019

Published online 4 Septem-

ber 2019

KEYWORDS

otitis media; biofilms; Streptococcus pneumoniae; Haemophilus influenzae; Moraxella catarrhalis

\section{Introduction}

Otitis media (OM) is a group of inflammatory disorders that affects the middle ear (ME) (Figure 1), being one of the most common diseases in childhood and a leading cause for medical consultation, antibiotic prescription and surgery procedures in young children. Different types of OM exist and are distinguished based on the presence of fluid in the ME with or without inflammation, the manifestation of symptoms and the appearance or perforation of the tympanic membrane (Schilder et al. 2016; Bergenfelz and Hakansson 2017).

Acute otitis media (AOM) is characterized by the rapid accumulation of fluid in the $M E$, with signs and symptoms of an acute infection, such as otalgia, otorrhea, fever and vomiting (Massa et al. 2009; Schilder et al. 2016). Globally, approximately 709 million cases of AOM occur each year, $51 \%$ of which affect children under 5 years-old (Monasta et al. 2012). The occurrence of more than 3 episodes of AOM in 6 months or of 4 or more episodes in 12 months is defined as recurrent AOM (RAOM), that is very common, causing much suffering for children and their parents (Schilder et al. 2016). For instance, the RAOM rate in children aged 3 and 5 years is estimated at about $50 \%$ and $65 \%$, respectively (Teele et al. 1989). Recurrence is very common in children attending day care centers, but also other risk factors (described below) can be associated with this occurrence (Schilder et al. 2016). Acute mastoiditis, a relatively rare but more serious complication of AOM, can also occur when the infection in the ME spreads to the mastoid air cells and covers the periosteum (Qureishi et al. 2014).

Otitis media with effusion (OME) is characterized by the presence of a glue-like fluid in the ME behind an intact tympanic membrane with no signs and symptoms of an acute infection. In a systematic literature review analyzing data from 63 different articles, it was shown that $28 \%$ cases had a spontaneous resolution by 3 months and increased to $42 \%$ by 6 months (Rosenfeld and Kay 2003). The most common symptom of OME is hearing loss, caused by an impaired transduction of sound waves due to the presence of ME effusion (MEE). Persistence of OME for 3 months or more is considered a chronic condition named chronic otitis media with effusion (COME). A persistent hearing loss may negatively impact speech development, behavior and progress at school (Qureishi et al. 2014; Schilder et al. 2016). OME is asymptomatic, and therefore the accurate determination of its incidence and prevalence is difficult. Nonetheless, estimates show that around $90 \%$ of children experience at least one case of OME before the school age (American Academy of Family Physicians et al. 2004).

CONTACT Sanna Sillankorva sanna.sillankorva@inl.int E CEB - Centre of Biological Engineering, LIBRO - Laboratório de Investigação em Biofilmes Rosário Oliveira, University of Minho, Braga 4710-057, Portugal

*Present address: INL - International Iberian Nanotechnology Laboratory, Avenida Mestre José Veiga, Braga, Portugal.

(1) Supplemental data for this article can be accessed here.

(C) 2019 Informa UK Limited, trading as Taylor \& Francis Group 


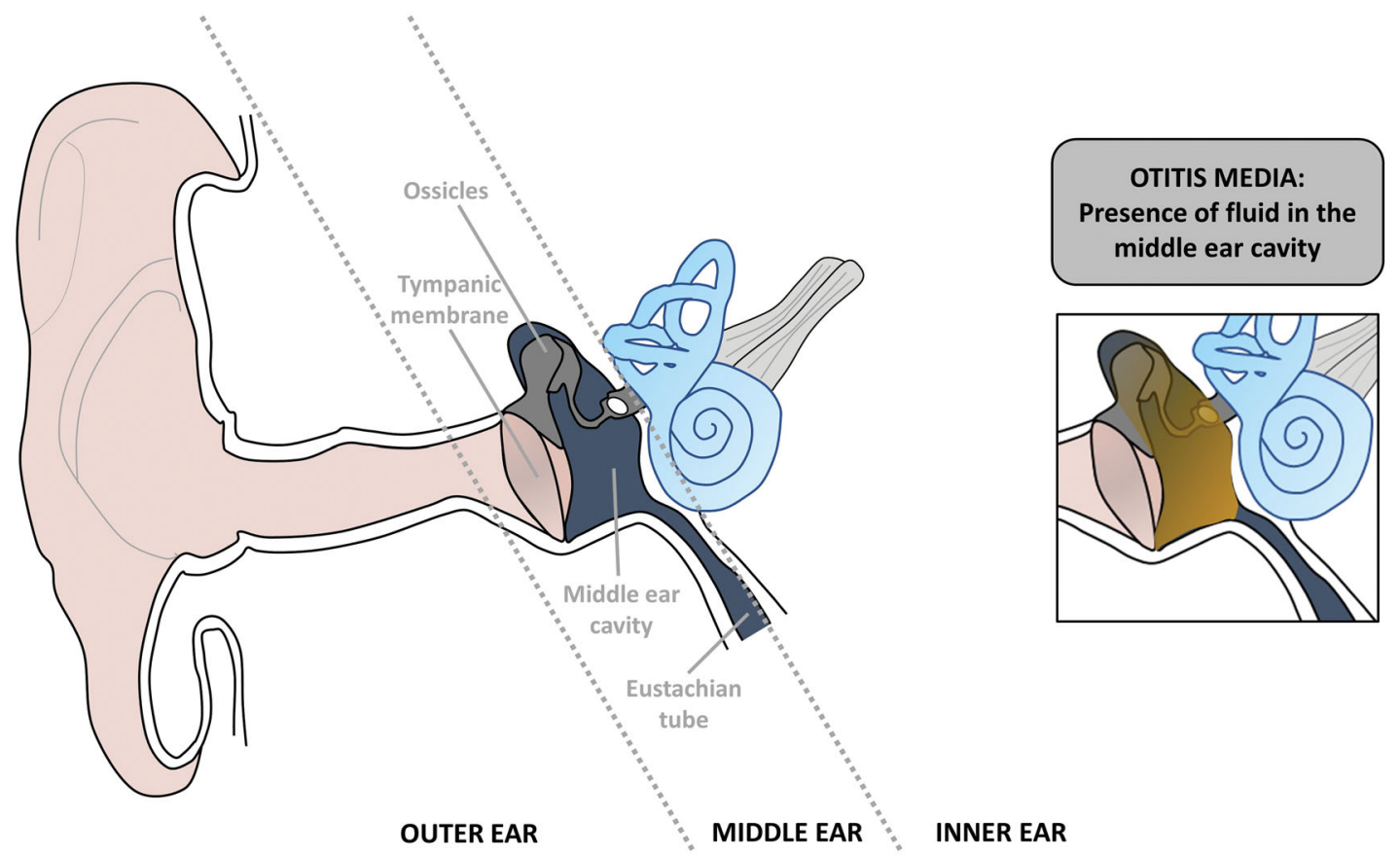

Figure 1. Anatomy of the human ear (outer, middle and inner ear) and representation of otitis media.

Chronic suppurative otitis media (CSOM) is based on the persistent presence of purulent MEE with, ordinarily, ear discharge through a tympanic membrane perforation (Qureishi et al. 2014; Schilder et al. 2016). Approximately 31 million cases of CSOM occur each year worldwide, with $22.6 \%$ affecting children under 5 years of age (Monasta et al. 2012).

Another OM complication is cholesteatoma, which is characterized by the presence of keratinizing squamous epithelium in the $M E$, manifesting as a chronic ear smelly ear discharge (Qureishi et al. 2014).

This review focuses on AOM and OME, their respective recurrence or chronicity and the microbiology associated due to their impact on children.

\section{Microbiology of otitis media}

Bacteria and viruses, individually or together, are associated with OM development. Haemophilus influenzae, Streptococcus pneumoniae and Moraxella catarrhalis are the most frequently identified otopathogens ( $\mathrm{Ngo}$ et al. 2016). Implementation of pneumococcal conjugate vaccines (PCVs) into national immunization programs has resulted in important changes in the microbiology of $\mathrm{OM}$. H. influenzae detection surpassed S. pneumoniae, becoming the most common causative agent worldwide. Furthermore, non-vaccine covered S. pneumoniae serotypes became the most commonly isolated serotypes from OM cases ( $\mathrm{Ngo}$ et al. 2016, Dagan et al. 2016). These bacterial species colonize the nasopharynx since early infancy and are considered part of the commensal flora, causing no harm until alterations occur in the nasopharyngeal milieu (Marom et al. 2012). Viruses, such as adenovirus, influenza virus types $A$ and $B$, respiratory syncytial virus, rhinovirus and parainfluenza virus, are also causative agents of $\mathrm{OM}$ (Chonmaitree et al. 2008).

Bacterial nasopharyngeal colonization transition to ME inflammation is highly correlated with concomitant upper viral respiratory tract infection (Heikkinen and Chonmaitree 2003). Viral infection of the nasopharynx alters the environment in this mucosa, modifying host immune function, inducing cytokine activity and inflammatory mediators, and increasing bacterial colonization and adherence to host cells through the upregulation of antigens that act as bacterial receptor sites (Bakaletz 2010). The properties of the mucus and its clearance by cells of the Eustachian tube (ET) and nasopharynx are also altered by the viral infection causing ET dysfunction and obstruction, originating a negative pressure in the ME that facilitates the influx of microorganisms to the ME cavity. Once in the ME, an inflammatory condition is established, inducing the disease (Marom et al. 2012). In a prospective longitudinal study of almost 300 children, $\mathrm{OM}$ incidence following an upper respiratory viral infection was of $61 \%$, with an AOM incidence of $37 \%$ and an OME incidence of $24 \%$ (Chonmaitree et al. 2008).

Infants and young children are more susceptible to OM due to the shorter, wider and more horizontal anatomy of the ET (Figure 2). The ET is responsible for the equalization of pressure, protection of the ME against 


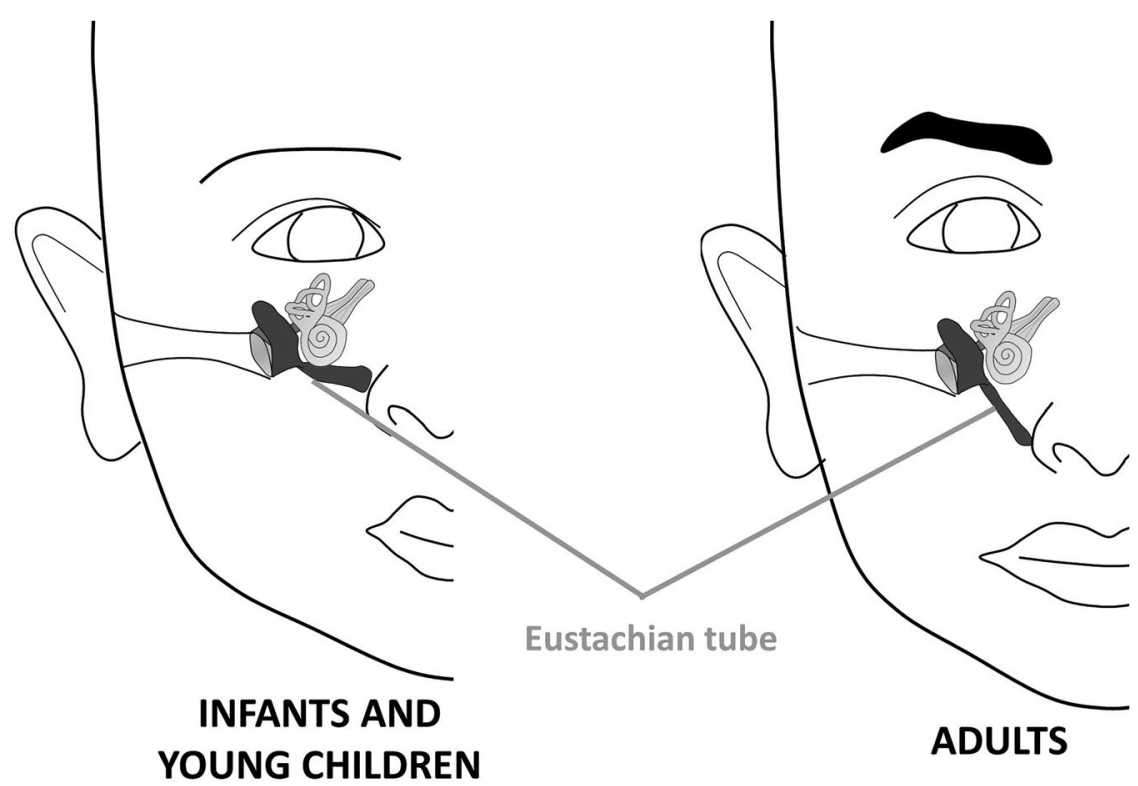

Figure 2. Differences in the anatomy of the Eustachian tube in infants and young children versus adults.

the influx of pathogens, and clearance of secretions. As the child grows, the ET matures, as well as the immune system, decreasing the risk of OM (Rovers et al. 2004; Qureishi et al. 2014; Schilder et al. 2016).

As a multifactorial disease, the risk of OM increases with many other aspects. These include host features, such as young age, male gender, genetics, family history of OM, craniofacial anomalies, allergies, immunodeficiency, and others. Also, environmental factors, including day care attendance, low socioeconomic status, tobacco smoke exposure, short duration of breastfeeding, use of pacifiers, among others, are associated with an increased incidence of OM (Rovers et al. 2004; Bakaletz 2010; Zhang et al. 2014; Kørvel-Hanquist et al. 2018).

\section{The biofilm nature of otitis media}

Over the last years the role of biofilms in OM has been demonstrated. Biofilms are communities of microorganisms embedded in a self-produced extracellular polymeric matrix (EPS) and attached to a surface (Figure 3) (Donlan 2002). Growth in biofilms is advantageous, protecting bacteria from environmental stresses, host immune defenses, and antimicrobial agents. Lower growth rates of bacteria within biofilms contribute also to their increased antimicrobial resistance (Donlan 2002; Stoodley et al. 2002). Metabolically inactive cells, called persister cells, play a major role in the recalcitrance of biofilms to antimicrobials (Lewis 2010). Biofilm formation is largely associated with an alteration in gene expression, with specific genes down- or up-regulated under control of a gene regulation system known as quorum sensing (QS) (Donlan 2002; Stoodley et al. 2002).

The biofilm nature of OM hypothesis evolved from a set of observations (Table 1). For many years, ME effusions collected from patients that were culture-negative were considered sterile. However, a significant percentage of bacterial DNA is today detected by polymerase chain reaction (PCR) methods in culturally sterile ME fluids (Post 1995). In a chinchilla model of OM, viable antibiotic-treated bacteria were detected by $P C R$ in contrast to purified DNA and DNA from intact but nonviable bacteria, which were not detected even following high copy inoculation (Post et al. 1996). Furthermore, the presence of bacterial mRNA by reverse-transcriptase PCR (RT-PCR) in culture negative otitis media effusions suggested the existence of metabolically active bacteria (Rayner et al. 1998). Formation of a $\mathrm{H}$. influenzae biofilms on the ME mucosa of chinchilla after bacterial injection reinforced that biofilms may play a role in the etiology of OM (Post 2001). Microscopy detection of biofilms on ME mucosa biopsy samples also supports the hypothesis that these disorders may be biofilm related (Hall-Stoodley et al. 2006).

Biofilm formation by pathogenic bacteria in the nasopharynx followed by shedding of biofilm cells has also been pointed as an important contributor to $\mathrm{OM}$, particularly AOM. Dispersed cells may enter into the ME cavity, taking advantage of the negative pressure in the ME due to ET dysfunction. Once in the ME, these bacteria can establish a new biofilm and induce disease. Since bacteria in biofilms can resist to the antimicrobial agents administered more effectively, 
Table 1. Studies supporting the hypothesis of the biofilm nature of OM.

\begin{tabular}{|c|c|c|c|c|}
\hline Sample & Origin & Species & Main results & Ref. \\
\hline MEF & Children with COME & $\begin{array}{l}\text { H. influenzae, S. pneumoniae, } \\
\text { M. catarrhalis }\end{array}$ & $\begin{array}{l}28.9 \% \text { of samples culture positive/PCR } \\
\text { positive; } 48 \% \text { of samples culture negative/ } \\
\text { PCR negative. }\end{array}$ & (Post 1995) \\
\hline MEF & Chinchilla model $^{a}$ & $\begin{array}{l}\text { Set } 1 \text { : live } H \text {. influenzae, } \\
\text { pasteurized } M \text {. catarrhalis } \\
\text { and purified S. pneumoniae } \\
\text { DNA } \\
\text { Set 2: live S. pneumoniae, } \\
\text { pasteurized } M \text {. catarrhalis } \\
\text { and purified } H \text {. } \\
\text { influenzae DNA }\end{array}$ & $\begin{array}{l}\text { PCR negative for detection of pasteurized } \\
\text { bacteria or purified DNA after day } 3 \text {; } \\
\text { PCR positive/culture negative for detection } \\
\text { of live bacteria until day } 21 \text {. }\end{array}$ & (Post et al. 1996) \\
\hline MEF & Children with COME & H. influenzae & $\begin{array}{l}11.8 \% \text { of samples culture positive/RT-PCR } \\
\text { positive; } 31.2 \% \text { of samples culture } \\
\text { negative/RT-PCR positive. }\end{array}$ & (Rayner et al. 1998) \\
\hline MEM & Chinchilla model $^{a}$ & H. influenzae & $\begin{array}{l}\text { Bacterial biofilms with increasing density and } \\
\text { thickness as time progresses observed on } \\
\text { MEM of chinchillas with experimental OM; } \\
\text { control chinchillas didn't show biofilms } \\
\text { on MEM. }\end{array}$ & (Post 2001) \\
\hline MEM & $\begin{array}{l}\text { Children with COME } \\
\text { or RAOM }\end{array}$ & $\begin{array}{l}\text { H. influenzae, S. pneumoniae, } \\
\text { M. catarrhalis }\end{array}$ & $\begin{array}{l}\text { Biofilms in } 92 \% \text { of samples that varied } \\
\text { in morphology }\end{array}$ & (Hall-Stoodley et al. 2006) \\
\hline
\end{tabular}

MEF: middle ear fluid; MEM: middle ear mucosa (biopsy samples); COME: chronic otitis media; RAOM: recurrent acute otitis media.

${ }^{a}$ Experimentally infected via transbullar injection.

recurrent episodes of OM (RAOM) are probable to occur (Coticchia et al. 2013).

Importantly, it is hypothesized that there is a continuum from early AOM episodes to more complex cases of COME that are usually linked with polymicrobial biofilms. Children had their first AOM case due to some genetic or environmental factor, with invasive strains of $S$. pneumoniae being frequently involved. This initial episode causes some mucosal damage that may predispose children to subsequent infections induced by pneumococcal serotypes with lower disease-inducing potential and other bacterial species such as $H$. influenzae and M. catarrhalis, with increased biofilm formation and polymicrobial interaction ability (Dagan et al. 2016).

\section{In vitro and in vivo biofilm studies}

\section{Haemophilus influenzae}

Several studies characterizing the biofilm phenotype of $H$. influenzae have been performed, using different microscopy techniques in vitro and in vivo (Table 2). Also, the role of diverse compounds from both bacterial and host origin that seem to impair in $\mathrm{H}$. influenzae biofilm phenotype and their impact in OM development and progression will be discussed.

H. influenzae strains ability to form robust biofilms with complex structures has been demonstrated in the ME of chinchilla. For instance, an increased bacterial density and development of a matrix-encased biofilm, consistent with the progression of time, was observed by scanning electron microscopy (SEM) in ME mucosal biopsy samples (Post 2001), or SEM and confocal laser scanning microscopy (CLSM) (Ehrlich et al. 2002). In the latter work, animals were killed at different time points with ME mucosal biopsy samples showing the evolution of biofilms from microcolony formation, characteristic of an early biofilm, to mature biofilms containing viable cells with an increased thickness and presence of water channels (Ehrlich et al. 2002).

ME mucosal biopsy samples of children with COME presented biofilms as demonstrated using generic stains and species-specific probes. Confocal images of the $H$. influenzae PCR positive samples showed matrixenclosed bacterial clusters, with a range of biofilm morphologies as observed by fluorescence in situ hybridization (FISH), (Hall-Stoodley et al. 2006). Biofilms formed by $\mathrm{ME}$ pathogens, including $H$. influenzae, were observed by SEM and CLSM coupled to FISH in the adenoids of children with RAOM, suggesting that biofilms in the nasopharynx act as reservoir for AOM recurrence (Hoa, Tomovic, et al. 2009). The presence of $H$. influenzae biofilms on the adenoids (Nistico et al. 2011) and in ME effusion samples (Van Hoecke et al. 2016) from patients with COME has also been reported. These data are in accordance with studies that report a stronger association of $H$. influenzae with RAOM and COME events. Although less-severe symptoms are detected, these cases are more difficult to treat and resolve properly (Barkai et al. 2009, Stol et al. 2013).

Besides addressing the presence of biofilms in $\mathrm{OM}$ samples, a few studies have also focused on the biofilm forming capacity of $H$. influenzae (Supplemental Table S1). Nontypeable $H$. influenzae (NTHi) clinical isolates 
Table 2. Microscopic detection of biofilms associated with otitis media.

\begin{tabular}{|c|c|c|c|c|}
\hline Sample & Origin & Species & Main results & Ref. \\
\hline MEM & Chinchilla model $^{a}$ & H. influenzae & $\begin{array}{l}\text { Bacterial biofilms with increasing } \\
\text { density and thickness as time } \\
\text { progresses observed on MEM of } \\
\text { chinchillas with experimental OM; } \\
\text { control chinchillas didn't show } \\
\text { biofilms on MEM. }\end{array}$ & (Post 2001) \\
\hline MEM & Chinchilla model $^{a}$ & H. influenzae & $\begin{array}{l}\text { Biofilms in all samples collected from } \\
\text { day } 1 \text { to } 21 \text {. Bacteria within biofilms } \\
\text { were viable. }\end{array}$ & (Ehrlich et al. 2002) \\
\hline MEM & $\begin{array}{l}\text { Children with COME } \\
\text { or RAOM }\end{array}$ & $\begin{array}{l}\text { H. influenzae, S. pneumoniae, } \\
\text { M. catarrhalis }\end{array}$ & $\begin{array}{l}\text { Biofilms on } 92 \% \text { of samples that varied } \\
\text { in morphology. }\end{array}$ & (Hall-Stoodley et al. 2006) \\
\hline MEM & Chinchilla model $^{\mathrm{a}}$ & S. pneumoniae & $\begin{array}{l}\text { Dense 3D structures containing viable } \\
\text { cells, and viable and non-viable host } \\
\text { cells attached to a fibrous } \\
\text { DNA matrix. }\end{array}$ & (Reid et al. 2009) \\
\hline Adenoids & Children with RAOM & $\begin{array}{l}\text { H. influenzae, S. pneumoniae, } \\
\text { M. catarrhalis, S. aureus }\end{array}$ & $\begin{array}{l}\text { Biofilm coverage higher than } 86 \% \text { in all } \\
\text { samples. Positive FISH staining for at } \\
\text { least one of the pathogens }\end{array}$ & (Hoa, Tomovic, et al. 2009) \\
\hline Adenoids and MEM & Chinchilla model $^{a}$ & S. pneumoniae & $\begin{array}{l}\text { Biofilms in NP (83\%) and MEF (67\%) } \\
\text { samples in chinchillas with } \\
\text { confirmed middle ear infection. All } \\
\text { animals with MEM biofilms had } \\
\text { biofilms in the NP. }\end{array}$ & (Hoa, Syamal, et al. 2009) \\
\hline Adenoids & $\begin{array}{l}\text { Children with COME } \\
\text { or OSA }\end{array}$ & Several & $\begin{array}{l}\text { Presence of several pathogens, with } \\
\text { higher frequency of } H \text {. influenzae in } \\
\text { COME cases than OSA. Aggregates of } \\
\text { viable bacteria encased in an } \\
\text { extracellular matrix consistent with } \\
\text { biofilm structures. }\end{array}$ & (Nistico et al. 2011) \\
\hline MEF and adenoids & Children with COME & H. influenzae & $\begin{array}{l}\text { H. influenzae specific aggregates, } \\
\text { indicative of biofilms, present in } 5 \\
\text { out of } 8 \text { culture positive samples, } \\
\text { but in none of the culture } \\
\text { negative samples. }\end{array}$ & (Van Hoecke et al. 2016) \\
\hline
\end{tabular}

MEF: middle ear fluid; MEM: middle ear mucosa (biopsy samples); NP: nasopharynx; COME: chronic otitis media; RAOM: recurrent acute otitis media; OSA: obstructive sleep apnea.

${ }^{a}$ Experimentally infected via transbullar injection.

had a remarkable variability in their capacity to form in vitro biofilms, with $\mathrm{P} 2, \mathrm{P} 5$ and $\mathrm{P} 6$ outer membrane proteins expressed during biofilm growth (Murphy and Kirkham 2002). In another study, more than $80 \%$ of NTHi isolated from AOM cases were shown to be good biofilm forming strains. Furthermore, the biofilm forming capacity of identical strains isolated both from ME fluid and nasopharynx was well correlated (Moriyama et al. 2009). Another interesting study showed that NTHi isolates collected from patients with invasive diseases and OM had a significant ability to form biofilms compared to isolates from other respiratory disease cases and healthy subjects, demonstrating that biofilms do play an important role on OM (Puig et al. 2014). In contrast, no association between biofilm formation by NTHi strains and AOM treatment failure or recurrence has also been reported (Mizrahi et al. 2014).

Several studies address the influence of specific moieties of lipooligosaccharides (LOS) on $\mathrm{H}$. influenzae biofilms. $H$. influenzae is not able to synthetize sialic (N-acetyl-neuraminic) acid but can acquire it from environmental sources and incorporate this important compound into its LOS structures. Sialylated LOS on
NTHi surface promotes biofilm formation in vitro (Swords et al. 2004). The NTHi 2019 strain produces a biofilm containing $\alpha 2,6$-linked sialic acid with levels of sialylated LOS increasing during biofilm growth (Greiner et al. 2004), and mutations in siaA, siaB, and wec $A$ resulted in diminished biofilm formation while mutations in $p g m$, lic $3 A$ and $l s g B$ resulted in equivalent or greater biofilms compared to NTHi 2019. A similar study performed in a chinchilla OM model showed that the wild type strain formed a large, well-organized, and viable biofilm, while mutants were either unable to form biofilms or formed biofilms of markedly reduced mass, organization, and viability (Jurcisek et al. 2005). Furthermore, some of the mutants survived in the chinchilla, inducing culture-positive ME effusions, while others were extremely sensitive to the bactericidal activity of chinchilla serum, indicating that LOS sialylation is indispensable for survivability of NTHi in vivo (Jurcisek et al. 2005).

Besides sialic acid, the impact of LOS containing phosphorylcholine (PCho) on $\mathrm{H}$. influenzae biofilms has been investigated. CLSM analysis of NTHi biofilms grown on epithelial cell surfaces revealed that LOS 
sialylated variants were distributed throughout the biofilm, while LOS variants expressing PCho were found within the biofilm (West-Barnette et al. 2006). Furthermore, these authors showed that LOS purified from NTHi biofilms or PCho positive strains were significantly less potent inducers of inflammatory responses than LOS purified from planktonic cultures or PCho negative strains, possibly justifying the quiescent periods of low-level inflammation that are typical of chronic NTHi infections. A study comparing the virulence of an OM isolate with that of a mutant lacking PCho showed that the mutant elicited an increased host inflammatory response early after challenge and induced a slower progression of disease in the chinchilla ME infection model (Hong, Mason, et al. 2007). In this study, differences in the presence and apparent density of biofilms formed in the ME of animals were noted, with PCho variants promoting biofilm formation. Similarly to the study by West-Barnette et al. (2006), NTHi biofilms formed within the chinchilla ME contained PCho positive variants within the biofilm structure. In a later study, the same research group concluded that PCho expression correlates with the maturation of NTHi biofilms, and may promote both in vitro and in vivo biofilm formation (Hong, Pang, et al. 2007).

Identification of proteins involved in biofilm formation and their distribution within biofilms is of utmost importance. For instance, peroxiredoxin-glutaredoxin protein was found to be present in greater abundance in $H$. influenzae biofilms compared to planktonic bacteria being directly involved in biofilm formation (Murphy et al. 2005). LOS were found to accumulate in the extracellular matrix at the base of the biofilm, with P6 outer membrane protein (OMP), a highly conserved protein in $\mathrm{H}$. influenzae able to stimulate macrophage and epithelial cells, localized in the membrane of what appear to be viable bacteria within the biofilm (Webster et al. 2006). Hap and HWM1/HMW2 adhesive proteins were found associated with bacteria within the biofilm and in the EPS, while Immunoglobin A1 protease was more concentrated in the top region of the biofilm possibly having a role in protecting bacteria from antibody attacks (Webster et al. 2006).

The chinchilla ME infection model was used to demonstrate that NTHi biofilms contain type IV pili and a significant amount of double-stranded DNA that may be conferring structural stability to biofilms (Jurcisek and Bakaletz 2007). Later, the same research group reported that PilA protein, and by inference type IV pili, played an important role in NTHi biofilm formation and adherence to epithelial cells in vitro, and that pilA genes were transcribed during colonization and infection with its expression being required for the formation of stable biofilms in vivo (Jurcisek et al. 2007). Another study also showed that the EPS matrix of NTHi biofilms is composed of proteins, nucleic acids and $\beta$-glucan, with eDNA being an important component of the EPS and essential in biofilm maintenance (Domenech et al. 2016). NTHi in vitro biofilms visualization combined with mathematical tools demonstrated that eDNA and type IV pili expression are both important for the development of fractal structures in these biofilms, and may help bacterial survival in hostile environments, such as the ME (Das et al. 2017).

The potential roles of neutrophil extracellular traps (NETs) by which neutrophils entrap bacteria by extrusion of their genomic DNA, aiming to kill them, has been observed for $H$. influenzae (Hong et al. 2009). Biofilms recovered from the ME of experimentally NTHi infected chinchillas showed viable host and bacterial cells within a fibrous DNA matrix and presence of elastase and histones within the biofilm structure, which is consistent with the existence of NETs. The contribution of LOS to $H$. influenzae survival in NETs was assessed by a bactericidal assay showing that NTHi with LOS mutations, in regions previously shown to promote biofilm formation, were more readily killed by NETs, and thus indicating that biofilm phenotype confers resistance to NETs (Hong et al. 2009).

The QS systems of $H$. influenzae have also been subject of research. The role of the luxS, the genetic determinant of the production of the auto-inducer-2 (Al-2) quorum signal, has been investigated, and the luxS mutant was found to produce an identical biofilm to that of the wild type strain but which tended to be more invasive to human cells, and also apparently more virulent in chinchilla (Daines et al. 2005). These authors concluded that the inactivation of the luxS gene results in dysregulation of pathways that are important in the pathogenesis of OM. In further studies, a significant reduction in thickness and overall density was observed in biofilms formed by the luxS mutant compared with the parental strain in vitro, and also in the chinchilla model (Armbruster et al. 2009), suggesting that luxS promotes biofilm maturation. Analysis of LOS composition by immunosorbent and immunoblotting assays revealed that luxS mutation resulted in a decreased content of PCho (Armbruster et al. 2009). RbsB protein was shown to mediate quorum signal uptake by binding to Al-2. Similarly to luxS mutants, rbsB mutants formed biofilms with reduced thickness and biomass, reduced PCho, and impaired bacterial persistence in the chinchilla ME, suggesting that $\mathrm{Al}-2$ quorum signaling is used by NTHi to promote biofilm formation and establishment of chronic 
infections (Armbruster et al. 2011). Recently, a glycosyltransferase which expression is increased by Al-2 production by NTHi, being involved in the synthesis of biofilm matrix, was identified (Pang et al. 2018).

In addition to the QS mechanism regulated by $\mathrm{Al}-2$ produced by luxS, the two-component signaling system QseB/C was also shown to be involved in NTHi biofilm formation. Deletion of the qseC gene resulted in a significant decrease of biofilm formation under different flow conditions, that were not correlated with Al-2 levels (Ünal et al. 2012).

The biofilm etiology in OM may explain the ineffectiveness of antibiotics in the treatment of this condition, due to the inherent inability of antibiotics to eradicate the biofilm bacteria. A decreased susceptibility of biofilm cells to antibiotics such as amoxicillin was shown using H. influenzae ME isolates (Slinger et al. 2006; Moriyama et al. 2009; Takei et al. 2013), with antibiotic combinations containing rifampin and ciprofloxacin being the most effective against $H$. influenzae biofilms (Slinger et al. 2006). Thus, it is important to continue to investigate efficient ways to eradicate this pathogen.

\section{Streptococcus pneumoniae}

Biofilm formation by $S$. pneumoniae has also been associated with OM. Herein, we will focus on studies performed over the last two decades that prove that S. pneumoniae forms well-organized biofilms both in the nasopharynx and in the $M E$, and further discuss the different factors that appear to influence pneumococcal biofilm formation and dispersal in these environments.

Microscopy techniques have shown pneumococcal biofilms both in the ME and nasopharyngeal samples (Table 2). S. pneumoniae biofilm structures were identified in the ME mucosa specimens of children diagnosed with COME. Analysis of S. pneumoniae PCR positive samples by CLSM revealed clusters of cocci apparently adhered to the ME mucosa and surrounded by an amorphous matrix. The presence of biofilms was also confirmed by FISH using a S. pneumoniae specific probe (Hall-Stoodley et al. 2006). The formation of S. pneumoniae biofilms in the ME of experimentally infected chinchilla was also reported. By different microscopic techniques, it was possible to observe viable pneumococcus, as wells as viable and nonviable host cells, entrapped in a fibrous matrix composed of DNA, indicating the existence of NETs (Reid et al. 2009).

Different microscopy techniques have been used to localize pneumococcal biofilms in samples collected from the adenoids of children with RAOM (Hoa, Tomovic, et al. 2009), and also in nasopharyngeal and
ME mucosal samples collected from infected chinchilla model after introducing a viral infection only then colonizing with the bacterial strain (Hoa, Syamal, et al. 2009).

Biofilm formation by S. pneumoniae has been a focus of study (Supplemental Table S2). The biofilm development process of distinct serotypes was characterized using a continuous-flow biofilm reactor system, and resulted in a three-stage biofilm formation that included initial attachment, cluster formation, and finally biofilm maturation (Allegrucci et al. 2006). This study showed that the architecture of the mature biofilms differed significantly among the serotypes tested and was correlated with proteomic changes, with a significant number of proteins detectable only on mature biofilms. Moreover, proteins involved in virulence, adhesion, and resistance were more abundant under biofilm growth conditions than planktonic conditions. More recently, protein profiles in planktonic and biofilm phenotypes were compared resulting in $80 \%$ of proteins differentially expressed during biofilm formation (Allan et al. 2014). These authors further observed that, in contrast to previously reported (Allegrucci et al. 2006), enzymes involved in the glycolytic pathway, in translation, transcription, and virulence were downregulated, while proteins associated with pyruvate, carbohydrate, and arginine metabolism pathways were more expressed during biofilm formation (Allan et al. 2014).

Studying gene products in biofilm formation demonstrated that choline-binding proteins are important for the biofilm development, with gene mutations resulting in decreased biofilm formation capacity (Moscoso et al. 2006). This study also showed that encapsulated strains have an impaired ability to form biofilms compared to non-typeable strains. Colony morphology variants with differences in colony size, capsule production and attachment occur in S. pneumoniae biofilm formation (Allegrucci and Sauer 2007). An analysis of biofilmphase variants differing in colony morphology revealed that most had mutations in the cps3D gene of the capsular operon (McEllistrem et al. 2007). Emergence of S. pneumoniae biofilm cell variants differing in capsule production, attachment, and biofilm formation was reported to occur due to an increased mutation rate affected by environmental conditions (Allegrucci and Sauer 2008), suggesting that biofilm development tends to select for unencapsulated (non-typeable) phenotypic variants. Biofilms formed by encapsulated pneumococcal nasopharyngeal isolates, under conditions that simulate those in the ME during $O M E$, presented a matrix composed of eDNA, and good biofilm formers further presented an enhanced structural complexity and increased antibiotic resistance 
(Hall-Stoodley et al. 2008). In addition, the cpsA gene of the capsular operon was downregulated in all S. pneumoniae biofilms compared to planktonic living. Biofilmforming capacity has been correlated with a reduction in colony size and in the relative amount of capsular polysaccharide present on the cell surface of S. pneumoniae biofilm colony variants (Domenech et al. 2009; Qin et al. 2013). Nonetheless, this was not a straightforward correlation since mutants with a low production of capsular polysaccharide and impaired biofilm formation were also found (Domenech et al. 2009). According to the authors, the heterogenous population was involved in different stages of the biofilm formation process, with the unencapsulated and good biofilm forming strains being essentially involved in the initial adhesion.

Today, there is sufficient evidence showing that eDNA, proteins and polysaccharides are, like in so many other bacterial species, also the main components of the S. pneumoniae biofilm matrix, and furthermore that strains with absent capsular polysaccharide form thicker biofilms (Domenech, García, et al. 2013). The reason why some specific serotypes are more prevalent in $\mathrm{OM}$ remains questionable. Capsular polysaccharide is considered the major virulence determinant of $S$. pneumoniae, existing more than 90 known serotypes (Gilley and Orihuela 2014). Some prevalent serotypes are reported to be good biofilm producers, and this may explain their high prevalence (Domenech et al. 2014; Domenech et al. 2015). Apparently, the chemical composition and structure of the capsular polysaccharide are important for the biofilm forming ability of different serotypes.

As discussed above, it is well established that $S$. pneumoniae colonization of the nasopharynx precedes the development of diseases such as OM (Hoa, Syamal, et al. 2009; Hoa, Tomovic, et al. 2009). Additionally, biofilm communities in the nasopharynx are a major source for horizontal genetic transference between pneumococcal strains (Marks et al. 2012; Wei and Håvarstein 2012). The sessile mode of living of S. pneumoniae is also advantageous with regards to evading the complement system and phagocytosis by human neutrophils (Domenech, Ramos-Sevillano, et al. 2013). Furthermore, cells released from nasopharyngeal biofilms can migrate to the ME where they will cause infection. Signals that induce dispersal of biofilms attached to epithelial cells, following an influenza A viral infection, include febrile-range temperatures, norepinephrine, extracytoplasmic ATP, and increased nutrient availability. These biofilm-released cells have phenotypic properties distinct from both biofilm and planktonic bacteria, with an increased capacity to disseminate and cause infection (Marks et al. 2013).
Another concern regarding S. pneumoniae in biofilms is its viability over extended periods, retaining their infection capacity (Marks et al. 2014). Secretions containing S. pneumoniae biofilms may be transferred via fomites from person to person and cause infection, which is very common to occur between children with OM attending day care centers (Marks et al. 2014).

The involvement of QS in the regulation of S. pneumoniae biofilm formation has also been studied. The effects of luxS expression and iron (in the form of Fe(III)) in biofilm development were found to be directly linked (Trappetti, Potter, et al. 2011). An overexpressing luxS mutant formed biofilms and supplementation with iron further enhanced biofilm formation. However, a luxSdefective mutant did not form biofilms even after iron supplementation. The luxS-dependent QS system is also a key regulator of early biofilm formation by S. pneumoniae (Vidal et al. 2011). These authors reported the construction of two luxS mutants that were unable to produce early biofilms, but this was reverted by genetic or physical complementation. Furthermore, transcription of lyt $A$ and ply (encoding the pneumococcal autolysin and pneumolysin, respectively) was found to be regulated by luxS (Vidal et al. 2011), and the role of Ply in early pneumococcal biofilm formation established (Shak et al. 2013). The LuxS/autoinducer 2 (Al-2) QS system, in which $\mathrm{Al}-2$ determined by luxS accumulates in the external milieu and stimulates planktonic bacteria to initiate early biofilm formation, was also shown essential for biofilm formation and colonization of the ME epithelium by S. pneumoniae (Yadav et al. 2018). S. pneumoniae biofilms are also regulated by the Com QS system known for mediating the genetic transference between cells. The induction of the Com system by the competence stimulating peptide (CSP), the product of comC gene, promotes biofilm formation in vitro (Oggioni et al. 2006), though its impacts depend on the biofilm model used (Trappetti, Gualdi, et al. 2011; Vidal et al. 2013). Expression of briC, which is induced by the competence system, was also shown to have an impact on late stages of biofilm formation, increasing biofilm biomass and thickness (Aggarwal et al. 2018). Recently, the role of the Rgg/small hydrophobic peptide (SHP) QS system in S. pneumoniae biofilms was pointed as responsible for the regulation of exopolysaccharide synthesis, and its overexpression resulted in the production of a ticker polysaccharide capsule and reduced biofilm formation (Junges et al. 2017).

Alike $H$. influenzae, S. pneumoniae biofilms are less susceptible to antibiotics than planktonic growing bacteria (del Prado et al. 2010; Matejka et al. 2012). The slower growth of bacterial cells, the presence of 
persister cells within the biofilm, the impaired antibiotic penetration through the biofilm matrix, among other factors, can affect the action of antibiotics (Takei et al. 2013). Despite the vast progress studying the specific role of biofilm cells and biofilm-released cells, as well as their interaction with the host during infection state there are still many questions that remain unanswered and need a deeper investigation.

\section{Moraxella catarrhalis}

Studies assessing the biofilm phenotype of $M$. catarrhalis are scarce. Despite this limited information, biofilm formation has been demonstrated in vitro, and biofilms have been detected in ME mucosal specimens of children with COME (Hall-Stoodley et al. 2006), and within adenoid biofilms of children with RAOM (Hoa, Tomovic, et al. 2009) (Table 2).

Addressing specifically $M$. catarrhalis biofilm formation (Supplemental Table S3), studies showed that UspA1 (Pearson et al. 2006), UspA2 (Verhaegh et al. 2008) and UspA2H proteins (Pearson and Hansen 2007), produced by only some $M$. catarrhalis strains, promote biofilm formation, while Hag protein inhibit biofilm formation (Pearson et al. 2006). Furthermore, M. catarrhalis isolates from children proved to have increased ability to form biofilms compared to adult isolates (Verhaegh et al. 2008).

Type IV pili play a role in $M$. catarrhalis biofilm formation, and mutants defective in type IV pili have impaired initial attachment, delayed microcolony formation and, diminished three-dimensional expansion (Luke et al. 2007). These authors showed multicellular mushroomshaped structures separated by water channels in wild type strain biofilms and significantly less-robust biofilm when mutants were used (Luke et al. 2007).

The genetic expression of $M$. catarrhalis planktonic and biofilm cells, analyzed using DNA microarrays and reverse transcriptase $P C R$, showed that genes associated with energy generation, i.e. genes involved in nitrate, nitrite, and nitric oxide reduction, are upregulated in the biofilm state (Wang et al. 2007). Investigating the Host factor $1(\mathrm{Hfq})$ protein, which function as an RNA chaperone that allows RNA-RNA interactions, in $M$. catarrhalis biofilm formation, it was observed that $h f q$ mutants exhibited a growth advantage possibly due to the increased expression or relative abundance of several outer membrane proteins (Attia et al. 2008). The extracellular nuclease NucM encoded by $M$. catarrhalis was shown to affect cell aggregation and biofilm formation, with nucM mutants biofilms having an increased biomass compared with wild type strain biofilms (Tan et al. 2019).
These works provide evidence that $M$. catarrhalis forms biofilms, nevertheless, a more comprehensive understanding of the factors triggering biofilm formation and dispersal and their involvement in $\mathrm{OM}$ is desirable.

\section{Multispecies}

Epidemiological studies demonstrate that OM infections can be polymicrobial in nature (Post 1995; Matar et al. 1998; Gok et al. 2001; Hall-Stoodley et al. 2006; Hoa, Tomovic, et al. 2009; Aly et al. 2012; Holder et al. 2015; Cilveti et al. 2017), however, the interspecies interaction has been addressed only in a few studies (Figure 4 and Supplemental Table S4).

A study using the chinchilla infection model was used to evaluate the impact of $H$. influenzae and $S$. pneumoniae coinfection (Weimer et al. 2010). The results showed that, using a ratio of $\mathrm{H}$. influenzae to $\mathrm{S}$. pneumoniae of either $1: 1$ or $10: 1,89 \%$ versus $50 \%$ of the ears of mixed and single infection animals contained biofilms. It has also been reported that the contact of NTHi and pneumococcus with epithelial cells leads to an increased multispecies biofilm formation (Krishnamurthy and Kyd 2014), and NTHi can even provide passive protection to $S$. pneumoniae from killing by amoxicillin (Murrah et al. 2015). H. influenzae and S. pneumoniae showed alterations in gene expression when in co-culture, but expression levels were also dependent of the growth environment with genes encoding lactose and glycerol utilization, and sugar transport proteins differing in the levels expressed (Tikhomirova et al. 2015). The biofilm forming ability of $H$. influenzae and S. pneumoniae strains isolated from the nasopharynx of children with AOM revealed that almost $65 \%$ of $\mathrm{H}$. influenzae and $67 \%$ of S. pneumoniae isolates produced biofilms (Vermee et al. 2019). Interestingly, better $H$. influenzae biofilm-producing strains were, in general, isolated from samples containing also S. pneumoniae but this correlation was not valid for S. pneumoniae strains.

$H$. influenzae and $M$. catarrhalis polymicrobial biofilms have an increased resistance towards antibiotics and host clearance compared to monospecies biofilms in chinchilla model of infection due to an interspecies QS process, in which $M$. catarrhalis uses $\mathrm{Al}-2$ produced by $\mathrm{H}$. influenzae to establish a persistent infection (Armbruster et al. 2010).

Multispecies biofilms by S. pneumoniae and M. catarrhalis showed that $M$. catarrhalis beta-lactamase production provided passive protection to $S$. pneumoniae against amoxicillin, and that $S$. pneumoniae increased the resistance of $M$. catarrhalis to azithromycin (Perez et al. 2014), with QS Al-2 having an important role in 


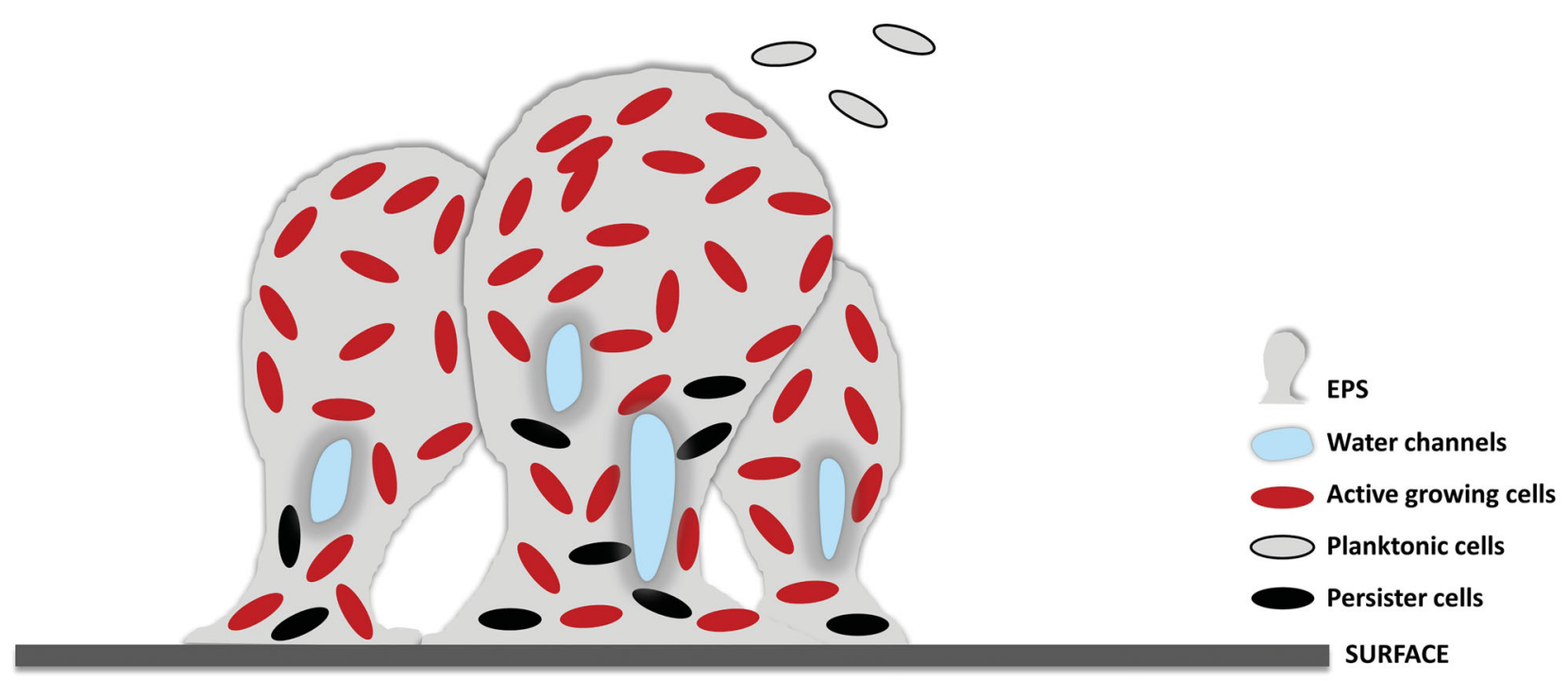

Figure 3. Representation of a mature biofilm.

\begin{tabular}{|c|c|}
\hline H. influenzae + S. pneumoniae & H. influenzae + M. catarrhalis \\
\hline $\begin{array}{l}\text { - Increased biofilm formation } \\
\text { - Protection against antibiotics }\end{array}$ & $\begin{array}{l}\text { - Protection against antibiotics } \\
\text { and host clearance } \\
\text { - QS used to establish } \\
\text { persistent infection }\end{array}$ \\
\hline \multicolumn{2}{|c|}{ MULTISPECIES BIOFILMS IN OM } \\
\hline S. pneumoniae + M. catarrhalis & H. influenzae + A. otitidis \\
\hline - Protection against antibiotics & $\begin{array}{l}\text { - Protection against antibiotics } \\
\text { - H. influenzae survival } \\
\text { promoted }\end{array}$ \\
\hline
\end{tabular}

Figure 4. Resume of the main findings of studies addressing multispecies biofilms in OM.

nasopharyngeal colonization and $\mathrm{ME}$ ascension during co-infections with both species (Perez et al. 2014).

Recently, the role of a less common OM pathogen, Alloiococcus otitidis, and its ability to form single and polymicrobial biofilms was investigated (Chan et al. 2017). A. otitidis is frequently detected by $P C R$ in $M E$ fluid samples, and multispecies biofilms formed together with $H$. influenzae resulted in a decreased antimicrobial susceptibility and promoted the survival of the latter species by increasing biofilm production in adverse conditions, such as depleted media and suboptimal growth temperature.

\section{Treatment of otitis media}

Current guidelines for the therapeutic management of ME infections depend on the type of OM that is diagnosed and are discussed below.
Management of symptoms such as ear pain and fever in AOM is made with analgesics, but the gold standard of treatment is, undoubtedly, the use of antibiotics (Figure 5). The majority of AOM cases resolve spontaneously and thus watchful waiting without immediate antibiotic prescription is recommended for nonsevere unilateral AOM in children 6 months to 23 months of age, and unilateral or bilateral nonsevere AOM in children with 24 months of age or older (Siddiq and Grainger 2015). In these cases, children must be followed up and antibiotherapy initiated if the symptoms do not improve in $48-72 \mathrm{~h}$. Children with 6 or more months of age having a diagnosis of unilateral or bilateral AOM together with manifestation of severe signs or symptoms require immediate antibiotic prescription (Siddiq and Grainger 2015). In addition, antibiotics should be used for the treatment of nonsevere bilateral AOM in children 6 months through 23 months of age 


\section{TREATMENT OF AOM}

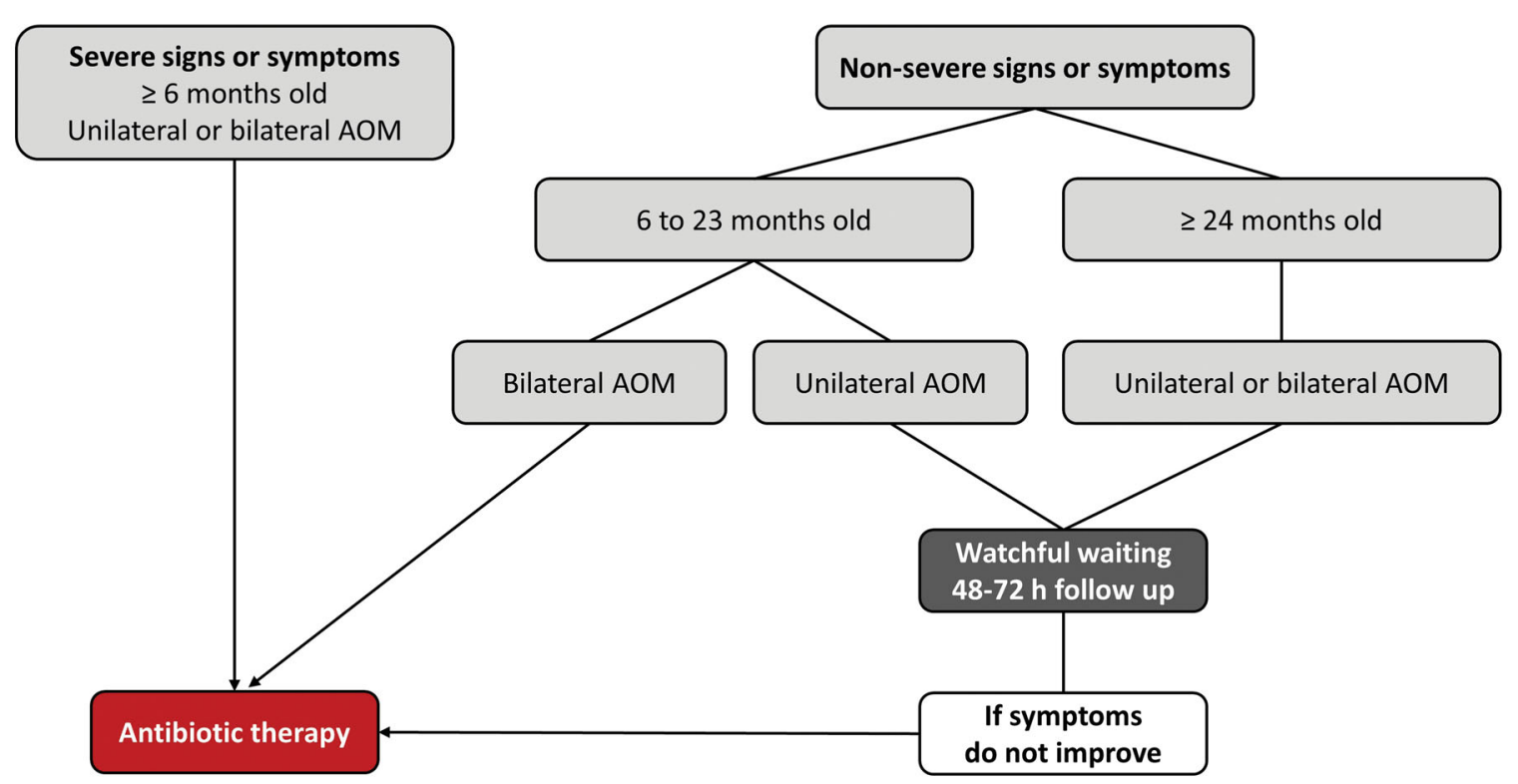

Figure 5. Guidelines for the treatment of AOM in children 6 months through 12 years of age.

(Siddiq and Grainger 2015). Amoxicillin at $80-90 \mathrm{mg} / \mathrm{kg} /$ day divided in two or three doses, is the drug of choice due to its low cost, acceptable taste, safety, effectiveness, and a narrow microbiologic spectrum (Harmes et al. 2013). Children having taken amoxicillin in the past 30 days, having conjunctivitis, or those needing coverage for $\beta$-lactamase-positive organisms (some $H$. influenzae isolates and universally all $M$. catarrhalis), should be prescribed with amoxicillin/clavulanic acid. Cephalosporins may be used in children presenting allergy to penicillin or in those that did not respond to the previous therapies. The use of nasal decongestants, antihistamines and corticosteroids is not recommended by the USA guidelines, since these have no apparent benefit (Siddiq and Grainger 2015).

For children with RAOM, myringotomy and insertion of a ventilation tube may be considered. In this surgery, a small incision is made in the tympanic membrane so that a tympanostomy tube can be inserted to enable ME fluid draining and improve its ventilation. Tympanostomy tubes usually stay in the tympanic membrane for 6 to 12 months and fall out themselves. Although a reduction in RAOM cases is observed with the prophylactic administration of antibiotics, these are not recommended due to their associated side effects (Harmes et al. 2013; Qureishi et al. 2014; Schilder et al. 2016).

In OME cases, a 3-month period of watchful waiting is recommended to evaluate the degree of hearing loss and its impact on speech, language and learning before treatment. According to the USA guidelines, besides decongestants, antihistamines and corticosteroids, antibiotics should also not be prescribed due to their low long-term outcome. When the ME effusion persists for more than 3 months (COME), myringotomy and ventilation tube insertion with or without adenoidectomy may be considered for the treatment of children (Harmes et al. 2013; Qureishi et al. 2014; Rosenfeld et al. 2016; Schilder et al. 2016).

\section{Novel strategies targeting otitis media biofilms}

The increasing antimicrobial resistance has forced a search for novel strategies to treat ME infections that focus on antibiofilm effects (Supplemental Table S5).

Disruption of the EPS, mostly by the interaction of compounds with the eDNA present within the $H$. influenzae biofilm matrix, is an example of antibiofilm focused research (Cavaliere et al. 2014). The main idea is to destabilize the EPS by targeting DNABII family of proteins, positioned at the vertices of crossed strands of eDNA. According to the authors, the use of a cation chelator (e.g. Ethylenediaminetetraacetic acid) was effective in both prevention and treatment of NTHi in vitro biofilms, and both EDTA and DNasel enhanced the efficacy of ampicillin and ciprofloxacin against NTHi biofilms. Antibodies against the Integration Host Factor (IHF) member of the DNABII family showed rapid disruption of NTHi biofilms in vitro (Goodman et al. 2011). Furthermore, the transcutaneous immunization with purified IHF of chinchillas with pre-formed NTHi biofilms resulted in a rapid disease resolution, and IHF antisera acted synergistically with amoxicillin. The 
mechanism of action of anti-IHF-mediated biofilm disruption is based on the sequestration of free IHF upon its dissociation from the eDNA matrix, forcing an equilibrium shift and ultimately, collapse of the biofilm (Brockson et al. 2014). Besides polyclonal antibodies action to disrupt NTHi biofilms, a cocktail of monoclonal antibodies directed against specific epitopes of the DNABII protein IHF was used to disrupt NTHi biofilms in the ME of the chinchilla infection model (Novotny et al. 2016). The treated chinchillas showed a marked reduction or complete eradication of biofilms in the ME with little to no residual signs of inflammation.

Antibiofilm therapeutic approaches have also focused on outer membrane proteins and adhesins expressed by NTHi, such as type IV pili (TFP) and OMP P5. Transcutaneous immunization with TFP and P5-targeted immunogens was effective in both prevention and treatment of NTHi biofilms in the ME of chinchillas (Novotny et al. 2011; Novotny, Clements, et al. 2015). Antibodies directed against TFP mediated gradual "topdown" dispersal of NTHi from the biofilms. In addition, dispersal was both TFP expression and LuxS Al-2 QS signaling molecules dependent (Novotny, Jurcisek, et al. 2015).

Natural and synthetic compounds have also been investigated for the control of biofilms formed by $\mathrm{H}$. influenzae. For instance, pyrazol derivatives (Kosikowska et al. 2014), chalcones (Kunthalert et al. 2014), plant extracts (Wajima et al. 2016), nitric oxide (Collins et al. 2016), proteins (Dawe et al. 2017), and honey (Newby et al. 2018), among others, have shown positive effects.

Antibiofilm experiments targeting $S$. pneumoniae have also been addressed. For instance, bacterial autolysin LytA and the and phage lysozymes Cpl-1 and Cpl-7 reduced around $80 \%, 70 \%$ and $55 \%$, respectively (Domenech et al. 2011). Other proposed alternative or adjuvant antimicrobial therapies to fight pneumococcal biofilms include xylitol (Kurola et al. 2011), HAMLET (a natural complex from human milk) (Laura R. Marks et al. 2012), plant extracts or essential oils (Yadav et al. 2013; Talekar et al. 2014; Minami et al. 2017), ceragenins (Moscoso et al. 2014), nitric oxide (Allan et al. 2016; Allan et al. 2017), zinc oxide nanoparticles (Bhattacharyya et al. 2018), flavonoids (Wang et al. 2018), and even human amniotic/chorionic membrane extracts (Yadav et al. 2017), among others.

PCVs are available for use in infants, young children, elderly, and children and adults who are at increased risk for getting pneumococcal disease. The current vaccine, PCV13, provides protection against 13 pneumococcal serotypes. Besides this, there is also available a pneumococcal polysaccharide vaccine (PPSV23) that provides protection to $23 \mathrm{~S}$. pneumoniae serotypes. However, this later vaccine is only recommended for elderly people and for children and adults older than 2 years that are at increased risk for disease (Centers for Disease Control and Prevention 2017). Widespread use of PCVs led to reductions in AOM episodes caused by vaccine-type $S$. pneumoniae serotypes, and it is hypothesized that this reduction can modify the continuum of otitis media pathogenesis, by decreasing the occurrence of early middle ear damage, subsequent OM episodes caused by non-vaccine pneumococcal serotypes as well as NTHi and M. catarrhalis, and also biofilm formation. Therefore, PCVs have an important role in the pathogenic progression of the disease when administered before the occurrence of any OM case. However, once initial damage occurs, PCVs cannot reduce disease beyond that caused by vaccine serotypes (Dagan et al. 2016).

M. catarrhalis antibiofilm strategies have not been extensively studied. Nevertheless, hyaluronic acid was found to reduce poorly (about 30\%) M. catarrhalis biofilms (Drago et al. 2014), while photodynamic therapy with porfimer sodium reduced by 3-4 logarithmic units the viable bacteria present in biofilms (Luke-Marshall et al. 2014).

Treatment of multispecies biofilms has been reported using antioxidant compounds, particularly $\mathrm{N}$ acetyl-L-cysteine and cysteamine (Domenech and García 2016), esters of bicyclic amines (Roig-Molina et al. 2019), and also antibodies against TFP of NTHi prevented and disrupted multispecies biofilms via an interspecies quorum signal at temperatures that mimic the nasopharynx $\left(34^{\circ} \mathrm{C}\right)$ or the $\mathrm{ME}\left(37^{\circ} \mathrm{C}\right)$ (Mokrzan et al. 2018).

Although some of the described approaches seem to be promising for the control of biofilms formed by otopathogens, to our knowledge none are currently undergoing clinical trials, and therefore, their potential clinical use might still be afar.

\section{Concluding remarks}

Investigations over the last years have proven that biofilms are associated with OM, contributing to its recurrence and chronicity. Understanding which factors influence biofilm formation and dispersal by the most common otopathogens as well as how they interact with each other and with the host enable the development of novel and targeted-therapeutic agents.

\section{Disclosure statement}

No potential conflict of interest was reported by the authors. 


\section{Funding}

MDS acknowledges the Portuguese Foundation for Science and Technology (FCT) grant [SFRH/BD/128825/2017]. This study was supported by the Portuguese Foundation for Science and Technology (FCT) under the scope of the strategic funding of [UID/BIO/04469/2019] unit and BioTecNorte operation [NORTE-01-0145-FEDER-000004] funded by the European Regional Development Fund under the scope of Norte2020 - Programa Operacional Regional do Norte.

\section{ORCID}

Maria Daniela Silva iD http://orcid.org/0000-0003-2495-6026 Sanna Sillankorva iD http://orcid.org/0000-0002-8408-8550

\section{References}

Aggarwal SD, Eutsey R, West-Roberts J, Domenech A, Xu W, Abdullah IT, Mitchell AP, Veening J-W, Yesilkaya H, Hiller NL. 2018. Function of BriC peptide in the pneumococcal competence and virulence portfolio. Mitchell TJ, editor. PLOS Pathog. 14(10):e1007328.

Allan RN, Kelso MJ, Rineh A, Yepuri NR, Feelisch M, Soren O, Brito-Mutunayagam S, Salib RJ, Stoodley P, Clarke SC. 2017. Cephalosporin-NO-donor prodrug PYRRO-C3D shows $\beta$-lactam-mediated activity against Streptococcus pneumoniae biofilms. Nitric Oxide - Biol Chem. 65:43-49.

Allan RN, Morgan S, Brito-Mutunayagam S, Skipp AP, Feelisch M, Hayes SM, Hellier W, Clarke SC, Stoodley P, Burgess A, et al. 2016. Low concentrations of nitric oxide modulate Streptococcus pneumoniae biofilm metabolism and antibiotic tolerance. Antimicrob Agents Chemother. 60(4): 2456-2466.

Allan RN, Skipp P, Jefferies J, Clarke SC, Faust SN, HallStoodley L, Webb J. 2014. Pronounced metabolic changes in adaptation to biofilm growth by Streptococcus pneumoniae. PLoS One. 4:194.

Allegrucci M, Hu FZ, Shen K, Hayes J, Ehrlich GD, Post JC, Sauer K. 2006. Phenotypic characterization of Streptococcus pneumoniae biofilm development. J Bacteriol. 188(7):2325-2335.

Allegrucci M, Sauer K. 2007. Characterization of colony morphology variants isolated from Streptococcus pneumoniae biofilms. J Bacteriol. 189(5):2030-2038.

Allegrucci M, Sauer K. 2008. Formation of Streptococcus pneumoniae non-phase-variable colony variants is due to increased mutation frequency present under biofilm growth conditions. J Bacteriol. 190(19):6330-6339.

Aly BH, Hamad MS, Mohey M, Amen S. 2012. Polymerase chain reaction (PCR) versus bacterial culture in detection of organisms in otitis media with effusion (OME) in children. Indian J Otolaryngol Head Neck Surg. 64(1):51-55.

American Academy of Family Physicians, American Academy of Otolaryngology-Head and Neck Surgery, American Academy of Pediatrics Subcommittee on Otitis Media With Effusion. 2004. Otitis media with effusion. Pediatrics. 113: 1412-1429.

Armbruster CE, Hong W, Pang B, Dew KE, Juneau RA, Byrd MS, Love CF, Kock ND, Swords WE. 2009. LuxS promotes biofilm maturation and persistence of nontypeable Haemophilus influenzae in vivo via modulation of lipooligosaccharides on the bacterial surface. Infect Immun. 77(9): 4081-4091.

Armbruster CE, Hong W, Pang B, Weimer KED, Juneau RA, Turner J, Swords WE. 2010. Indirect pathogenicity of Haemophilus influenzae and Moraxella catarrhalis in polymicrobial otitis media occurs via interspecies quorum signaling. MBio. 1(3):e00102-10-e00102-19.

Armbruster $C E$, Pang $B$, Murrah $K$, Juneau RA, Perez AC, Weimer KED, Swords WE. 2011. RbsB (NTHI-0632) mediates quorum signal uptake in nontypeable Haemophilus influenzae strain 86-028NP. Mol Microbiol. 82(4):836-850.

Attia AS, Sedillo JL, Wang W, Liu W, Brautigam CA, Winkler W, Hansen EJ. 2008. Moraxella catarrhalis expresses an unusual Hfq protein. Infect Immun. 76(6):2520-2530.

Bakaletz LO. 2010. Immunopathogenesis of polymicrobial otitis media. J Leukoc Biol. 87(2):213-222.

Barkai G, Leibovitz E, Givon-Lavi N, Dagan R. 2009. Potential contribution by Nontypable Haemophilus influenzae in protracted and recurrent acute otitis media. Pediatr Infect Dis J. 28(6):466-471.

Bergenfelz C, Hakansson AP. 2017. Streptococcus pneumoniae otitis media pathogenesis and how it informs our understanding of vaccine strategies. Curr Otorhinolaryngol Rep. 5(2):115-124.

Bhattacharyya P, Agarwal B, Goswami M, Maiti D, Baruah S, Tribedi P. 2018. Zinc oxide nanoparticle inhibits the biofilm formation of Streptococcus pneumoniae. Antonie Van Leeuwenhoek. 111(1):89-99.

Brockson ME, Novotny LA, Mokrzan EM, Malhotra S, Jurcisek JA, Akbar R, Devaraj A, Goodman SD, Bakaletz LO. 2014. Evaluation of the kinetics and mechanism of action of anti-integration host factor-mediated disruption of bacterial biofilms. Mol Microbiol. 93(6):1246-1258.

Cavaliere R, Ball JL, Turnbull L, Whitchurch CB. 2014. The biofilm matrix destabilizers, EDTA and DNasel, enhance the susceptibility of nontypeable Hemophilus influenzae biofilms to treatment with ampicillin and ciprofloxacin. Microbiologyopen. 3(4):557-567.

Centers for Disease Control and Prevention. 2017. Pneumococcal vaccination [Internet]. Available from: https://www.cdc.gov/pneumococcal/vaccination.html

Chan CL, Richter K, Wormald P-J, Psaltis AJ, Vreugde S. 2017. Alloiococcus otitidis forms multispecies biofilm with Haemophilus influenzae: effects on antibiotic susceptibility and growth in adverse conditions. Front Cell Infect Microbiol. 7:344.

Chonmaitree T, Revai K, Grady JJ, Clos A, Patel JA, Nair S, Fan J, Henrickson KJ. 2008. Viral upper respiratory tract infection and otitis media complication in young children. Clin Infect Dis. 46(6):815-823.

Cilveti R, Olmo M, Pérez-Jove J, Picazo JJ, Arimany JL, Mora E, Pérez-Porcuna TM, Aguilar I, Alonso A, Molina F, et al. 2017. Epidemiology of otitis media with spontaneous perforation of the tympanic membrane in young children and association with bacterial nasopharyngeal carriage, recurrences and pneumococcal vaccination in Catalonia, Spain The prospective Hermes study. PLoS One. 12(2): e0170316-16.

Collins SA, Kelso MJ, Rineh A, Yepuri NR, Coles J, Jackson CL, Halladay GD, Walker WT, Webb JS, Hall-Stoodley L, et al. 
2016. Cephalosporin-3' -diazeniumdiolate NO-donor prodrug PYRRO-C3D enhances azithromycin susceptibility of nontypeable Haemophilus influenzae biofilms. Antimicrob Agents Chemother. 61:AAC.02086-16.

Coticchia JM, Chen M, Sachdeva L, Mutchnick S. 2013. New paradigms in the pathogenesis of otitis media in children. Front Pediatr. 1:1-7.

Dagan R, Pelton S, Bakaletz L, Cohen R. 2016. Prevention of early episodes of otitis media by pneumococcal vaccines might reduce progression to complex disease. Lancet Infect Dis. 16(4):480-492.

Daines DA, Bothwell M, Furrer J, Unrath W, Nelson K, Jarisch J, Melrose N, Greiner L, Apicella M, Smith AL. 2005. Haemophilus influenzae luxS mutants form a biofilm and have increased virulence. Microb Pathog. 39(3):87-96.

Das J, Mokrzan E, Lakhani V, Rosas L, Jurcisek JA, Ray WC, Bakaletz LO. 2017. Extracellular DNA and type IV pilus expression regulate the structure and kinetics of biofilm formation by nontypeable Haemophilus influenzae. MBio. 8(6):1-19.

Dawe $H$, Berger E, Sihlbom C, Angus EM, Howlin RP, Laver JR, Tebruegge M, Hall-Stoodley L, Stoodley P, Faust SN, Allan RN. 2017. D-methionine interferes with nontypeable Haemophilus influenzae peptidoglycan synthesis during growth and biofilm formation. Microbiol. 163:1093-1104.

Domenech M, Araújo-Bazán L, García E, Moscoso M. 2014. In vitro biofilm formation by Streptococcus pneumoniae as a predictor of post-vaccination emerging serotypes colonizing the human nasopharynx. Environ Microbiol. 16(4): 1193-1201.

Domenech M, Damián D, Ardanuy C, Liñares J, Fenoll A, García E. 2015. Emerging, non-PCV13 serotypes $11 \mathrm{~A}$ and 35B of Streptococcus pneumoniae show high potential for biofilm formation in vitro. PLoS One. 10(4):e0125636-11.

Domenech M, García E. 2016. N -Acetyl-L-cysteine and Cysteamine: new Strategies Against Mixed Biofilms of nonencapsulated Streptococcus pneumoniae and nontypeable Haemophilus influenzae. Antimicrob Agents Chemother. 61: AAC.01992-16.

Domenech M, Garciá E, Moscoso M. 2011. In vitro destruction of Streptococcus pneumoniae biofilms with bacterial and phage peptidoglycan hydrolases. Antimicrob Agents Chemother. 55(9):4144-4148.

Domenech M, García E, Moscoso M. 2009. Versatility of the capsular genes during biofilm formation by Streptococcus pneumoniae. Environ Microbiol. 11(10):2542-2555.

Domenech M, García E, Prieto A, Moscoso M. 2013. Insight into the composition of the intercellular matrix of Streptococcus pneumoniae biofilms. Environ Microbiol. 15(2):502-516.

Domenech M, Pedrero-Vega E, Prieto A, García E. 2016. Evidence of the presence of nucleic acids and $\beta$-glucan in the matrix of nontypeable Haemophilus influenzae in vitro biofilms. Sci Rep. 6(1):1-13.

Domenech M, Ramos-Sevillano E, García E, Moscoso M, Yuste J. 2013. Biofilm formation avoids complement immunity and phagocytosis of Streptococcus pneumoniae. Infect Immun. 81(7):2606-2615.

Donlan RM. 2002. Biofilms: microbial life on surfaces. Emerging Infect Dis. 8(9):881-890.

Drago L, Cappelletti L, De Vecchi E, Pignataro L, Torretta S, Mattina R. 2014. Antiadhesive and antibiofilm activity of hyaluronic acid against bacteria responsible for respiratory tract infections. APMIS. 122(10):1013-1019.

Ehrlich GD, Veeh R, Wang X, Costerton JW, Hayes JD, Hu FZ, Daigle BJ, Ehrlich MD, Post JC. 2002. Mucosal biofilm formation on middle-ear mucosa in the chinchilla model of otitis media. JAMA. 287(13):1710-1715.

Gilley RP, Orihuela CJ. 2014. Pneumococci in biofilms are non-invasive: implications on nasopharyngeal colonization. Front Cell Infect Microbiol. 4:2010-2015.

Gok U, Doymaz MZ, Bulut Y, Keles E, Yalcin S. 2001. Bacteriological and PCR analysis of clinical material aspirated from otitis media with effusions. Int J Pediat Otorhinolaryngol. 60(1):49-54.

Goodman SD, Obergfell KP, Jurcisek JA, Novotny LA, Downey JS, Ayala EA, Tjokro N, Li B, Justice SS, Bakaletz LO. 2011. Biofilms can be dispersed by focusing the immune system on a common family of bacterial nucleoid-associated proteins. Mucosal Immunol. 4(6):625-637.

Greiner LL, Watanabe H, Phillips NJ, Shao J, Morgan A, Zaleski A, Gibson BW, Apicella MA. 2004. Nontypeable Haemophilus influenzae strain 2019 produces a biofilm containing $\mathrm{N}$-acetylneuraminic acid that may mimic sialylated O-linked glycans. Infect Immun. 72(7):4249-4260.

Hall-Stoodley L, Hu FZ, Gieseke A, Nistico L, Nguyen D, Hayes J, Forbes M, Greenberg DP, Dice B, Burrows A, et al. 2006. Direct detection of bacterial biofilms on the middle-ear mucosa of children with chronic otitis media. JAMA. 296(2):202

Hall-Stoodley L, Nistico L, Sambanthamoorthy K, Dice B, Nguyen D, Mershon WJ, Johnson C, Hu FZ, Stoodley P, Ehrlich GD, Post JC. 2008. Characterization of biofilm matrix, degradation by DNase treatment and evidence of capsule downregulation in Streptococcus pneumoniae clinical isolates. BMC Microbiol. 8(1):173-116.

Harmes KM, Blackwood RA, Burrows HL, Cooke JM, Van Harrison R, Passamani PP. 2013. Otitis media: diagnosis and treatment. Am Fam Physician. 88(7):435-440.

Heikkinen T, Chonmaitree T. 2003. Importance of respiratory viruses in acute otitis media. Clin Microbiol Rev. 16(2): 230-241.

Hoa M, Syamal M, Sachdeva L, Berk R, Coticchia J. 2009. Demonstration of nasopharyngeal and middle ear mucosal biofilms in an animal model of acute otitis media. Ann Otol Rhinol Laryngol. 118(4):292-298.

Hoa M, Tomovic S, Nistico L, Hall-Stoodley L, Stoodley P, Sachdeva L, Berk R, Coticchia JM. 2009. Identification of adenoid biofilms with middle ear pathogens in otitisprone children utilizing SEM and FISH. Int J Pediatr Otorhinolaryngol. 73(9):1242-1248.

Van Hoecke H, De Paepe A-S, Lambert E, Van Belleghem JD, Cools P, Van Simaey L, Deschaght P, Vaneechoutte $M$, Dhooge I. 2016. Haemophilus influenzae biofilm formation in chronic otitis media with effusion. Eur Arch Otorhinolaryngol. 273(11):3553-3560.

Holder RC, Kirse DJ, Evans AK, Whigham AS, Peters TR, Poehling KA, Swords WE, Reid SD. 2015. Otopathogens detected in middle ear fluid obtained during tympanostomy tube insertion: contrasting purulent and non-purulent effusions. PLoS One. 10(6):e0128606-9.

Hong W, Juneau RA, Pang B, Swords WE. 2009. Survival of bacterial biofilms within neutrophil extracellular traps promotes nontypeable Haemophilus influenzae Persistence in 
the chinchilla model for otitis media. J Innate Immun. 1(3): 215-224.

Hong W, Mason K, Jurcisek J, Novotny L, Bakaletz LO, Swords WE. 2007. Phosphorylcholine decreases early inflammation and promotes the establishment of stable biofilm communities of nontypeable Haemophilus influenzae strain 86028NP in a chinchilla model of otitis media. Infect Immun. 75(2):958-965.

Hong W, Pang B, West-Barnette S, Swords WE. 2007. Phosphorylcholine expression by nontypeable Haemophilus influenzae correlates with maturation of biofilm communities in vitro and in vivo. J Bacteriol. 189(22): 8300-8307.

Junges R, Salvadori G, Shekhar S, Åmdal HA, Periselneris JN, Chen T, Brown JS, Petersen FC. 2017. A quorum-sensing system that regulates Streptococcus pneumoniae biofilm formation and surface polysaccharide production. mSphere. 2(5):1-18.

Jurcisek J, Greiner L, Watanabe H, Zaleski A, Apicella MA, Lauren O, Bakaletz LO. 2005. Role of sialic acid and complex carbohydrate biosynthesis in biofilm formation by nontypeable Haemophilus influenzae in the chinchilla middle ear. Infect Immun. 73(6):3210-3218.

Jurcisek JA, Bakaletz LO. 2007. Biofilms formed by nontypeable Haemophilus influenzae in vivo contain both doublestranded DNA and type IV pilin protein. J Bacteriol. 189(10):3868-3875.

Jurcisek JA, Bookwalter JE, Baker BD, Fernandez S, Novotny LA, Munson RS, Bakaletz LO. 2007. The PilA protein of nontypeable Haemophilus influenzae plays a role in biofilm formation, adherence to epithelial cells and colonization of the mammalian upper respiratory tract. Mol Microbiol. 65(5):1288-1299.

Kørvel-Hanquist A, Koch A, Lous J, Olsen SF, Homøe P. 2018. Risk of childhood otitis media with focus on potentially modifiable factors: a Danish follow-up cohort study. Int J Pediatr Otorhinolaryngol. 106:1-9.

Kosikowska U, Malm A, Pitucha M, Rajtar B, Polz-Dacewicz M. 2014. Inhibitory effect of N-ethyl-3-amino-5-oxo-4-phenyl2,5-dihydro-1H-pyrazole-1-carbothioamide

on Haemophilus spp. planktonic or biofilm-forming cells. Med Chem Res. 23:1057-1066.

Krishnamurthy A, Kyd J. 2014. The roles of epithelial cell contact, respiratory bacterial interactions and phosphorylcholine in promoting biofilm formation by Streptococcus pneumoniae and nontypeable Haemophilus influenzae. Microbes Infect. 16(8):640-647.

Kunthalert D, Baothong S, Khetkam P, Chokchaisiri S, Suksamrarn A. 2014. A chalcone with potent inhibiting activity against biofilm formation by nontypeable Haemophilus influenzae. Microbiol Immunol. 58(10): 581-589.

Kurola $P$, Tapiainen T, Sevander J, Kaijalainen T, Leinonen $M$, Uhari M, Saukkoriipi A. 2011. Effect of xylitol and other carbon sources on Streptococcus pneumoniae biofilm formation and gene expression in vitro. APMIS. 119(2): 135-142.

Lewis K. 2010. Persister cells. Annu Rev Microbiol. 64: 357-372.

Luke-Marshall NR, Mang TS, Hansen LA, Campagnari AA. 2014. Moraxella catarrhalis is susceptible to antimicrobial photodynamic therapy with Photofrin. Lasers Surg Med. 46(9):712-717.

Luke NR, Jurcisek JA, Bakaletz LO, Campagnari AA. 2007. Contribution of Moraxella catarrhalis type IV pili to nasopharyngeal colonization and biofilm formation. Infect Immun. 75(12):5559-5564.

Marks LR, Clementi EA, Hakansson AP. 2012. The human milk protein-lipid complex HAMLET sensitizes bacterial pathogens to traditional antimicrobial agents. PLoS One. 7(8): e43514.

Marks LR, Davidson BA, Knight PR, Hakansson AP. 2013. Interkingdom signaling induces Streptococcus pneumoniae biofilm dispersion and transition from asymptomatic colonization to disease. MBio. 4(4):1-13.

Marks LR, Reddinger RM, Anders P. 2012. High levels of genetic recombination during nasopharyngeal carriage and biofilm formation in Streptococcus pneumoniae. MBio. 3(5): e00200-12.

Marks LR, Reddinger RM, Hakansson AP. 2014. Biofilm formation enhances fomite survival of Streptococcus pneumoniae and Streptococcus pyogenes. Infect Immun. 82(3): 1141-1146.

Marom T, Nokso-Koivisto J, Chonmaitree T. 2012. Viral-bacterial interactions in acute otitis media. Curr Allergy Asthma Rep. 12(6):551-558.

Massa HM, Cripps AW, Lehmann D. 2009. Otitis media: viruses, bacteria, biofilms and vaccines. Med J Aust. 191: 4-9.

Matar GM, Sidani N, Fayad M, Hadi U. 1998. Two-step PCRbased assay for identification of bacterial etiology of otitis media with effusion in infected Lebanese children. J Clin Microbiol. 36(5):1185-1188.

Matejka KM, Bremer PJ, Tompkins GR, Brooks H. 2012. Antibiotic susceptibility of Moraxella catarrhalis biofilms in a continuous flow model. Diagn Microbiol Infect Dis. 74(4): 394-398.

McEllistrem MC, Ransford JV, Khan SA. 2007. Characterization of in vitro biofilm-associated pneumococcal phase variants of a clinically relevant serotype 3 clone. J Clin Microbiol. 45(1):97-101.

Minami M, Konishi T, Takase H, Makino T. 2017. Shin'iseihaito (Xinyiqingfeitang) suppresses the biofilm formation of Streptococcus pneumoniae in vitro. 2017. Biomed Res Int. 2017:4575709.

Mizrahi A, Cohen R, Varon E, Bonacorsi S, Bechet S, Poyart C, Levy C, Raymond J. 2014. Non typable-Haemophilus influenzae biofilm formation and acute otitis media. BMC Infect Dis. 14:400.

Mokrzan EM, Novotny LA, Brockman KL, Bakaletz LO. 2018. Antibodies against the majority subunit (PilA) of the type IV pilus of nontypeable Haemophilus influenzae disperse Moraxella catarrhalis from a dual-Species biofilm. MBio. 9(6):1-18.

Monasta L, Ronfani L, Marchetti F, Montico M, Vecchi Brumatti L, Bavcar A, Grasso D, Barbiero C, Tamburlini G. 2012. Burden of disease caused by otitis media: systematic review and global estimates. PLoS One. 7(4):e36226.

Moriyama S, Hotomi M, Shimada J, Billal DS, Fujihara K, Yamanaka N. 2009. Formation of biofilm by Haemophilus influenzae isolated from pediatric intractable otitis media. Auris Nasus Larynx. 36(5):525-531. 
Moscoso M, Esteban-Torres M, Menéndez M, García E. 2014. In vitro bactericidal and bacteriolytic activity of ceragenin CSA-13 against planktonic cultures and biofilms of Streptococcus pneumoniae and other pathogenic streptococci. PLoS One. 9(7):e101037.

Moscoso M, García E, López R. 2006. Biofilm formation by Streptococcus pneumoniae: role of choline, extracellular DNA, and capsular polysaccharide in microbial accretion. J Bacteriol. 188(22):7785-7795.

Murphy TF, Kirkham C. 2002. Biofilm formation by nontypeable Haemophilus influenzae: strain variability, outer membrane antigen expression and role of pili. BMC Microbiol. 2(1):7-8.

Murphy TF, Kirkham C, Sethi S, Lesse AJ. 2005. Expression of a peroxiredoxin-glutaredoxin by Haemophilus influenzae in biofilms and during human respiratory tract infection. FEMS Immunol Med Microbiol. 44(1):81-89.

Murrah KA, Pang B, Richardson S, Perez A, Reimche J, King L, Wren J, Swords WE. 2015. Nonencapsulated Streptococcus pneumoniae causes otitis media during single-species infection and during polymicrobial infection with nontypeable Haemophilus influenzae. Pathog Dis. 73:1-8.

Newby RS, Dryden M, Allan RN, Salib RJ. 2018. Antimicrobial activity of a novel bioengineered honey against non-typeable Haemophilus influenzae biofilms: an in vitro study. J Clin Pathol. 71(6):554-558.

Ngo CC, Massa HM, Thornton RB, Cripps AW. 2016. Predominant bacteria detected from the middle ear fluid of children experiencing otitis media: a systematic review. PLoS One. 11(3):e0150949.

Nistico L, Kreft R, Gieseke A, Coticchia JM, Burrows A, Khampang P, Liu Y, Kerschner JE, Post JC, Lonergan S, et al. 2011. Adenoid reservoir for pathogenic biofilm bacteria. J Clin Microbiol. 49(4):1411-1420.

Novotny LA, Clements JD, Bakaletz LO. 2011. Transcutaneous immunization as preventative and therapeutic regimens to protect against experimental otitis media due to nontypeable Haemophilus influenzae. Mucosal Immunol. 4(4): 456-467.

Novotny LA, Clements JD, Bakaletz LO. 2015. Therapeutic transcutaneous immunization with a band-aid vaccine resolves experimental otitis media. Clin Vaccine Immunol. 22(8):867-874.

Novotny LA, Jurcisek JA, Goodman SD, Bakaletz LO. 2016. Monoclonal antibodies against DNA-binding tips of DNABII proteins disrupt biofilms in vitro and induce bacterial clearance in vivo. EBioMedicine. 10:33-44.

Novotny LA, Jurcisek JA, Ward MO, Jordan ZB, Goodman SD, Bakaletz LO. 2015. Antibodies against the majority subunit of type IV pili disperse nontypeable Haemophilus influenzae biofilms in a LuxS-dependent manner and confer therapeutic resolution of experimental otitis media. Mol Microbiol. 96(2):276-292.

Oggioni MR, Trappetti C, Kadioglu A, Cassone M, lannelli F, Ricci S, Andrew PW, Pozzi G. 2006. Switch from planktonic to sessile life: a major event in pneumococcal pathogenesis. Mol Microbiol. 61(5):1196-1210.

Pang B, Armbruster CE, Foster G, Learman BS, Gandhi U, Swords WE. 2018. Autoinducer 2 (Al-2) production by nontypeable Haemophilus influenzae 86-028NP promotes expression of a predicted glycosyltransferase that is a determinant of biofilm maturation, prevention of dispersal, and persistence in vivo. Infect Immun. 86(12):e00506-18.

Pearson MM, Hansen EJ. 2007. Identification of gene products involved in biofilm production by Moraxella catarrhalis ETSU-9 in vitro. Infect Immun. 75(9):4316-4325.

Pearson MM, Laurence CA, Guinn SE, Hansen EJ. 2006. Biofilm formation by Moraxella catarrhalis in vitro: roles of the UspA1 adhesin and the Hag hemagglutinin. Infect Immun. 74(3):1588-1596.

Perez AC, Pang B, King LB, Tan L, Murrah KA, Reimche JL, Wren JT, Richardson SH, Ghandi U, Swords WE. 2014. Residence of Streptococcus pneumoniae and Moraxella catarhalis within polymicrobial biofilm promotes antibiotic resistance and bacterial persistence in vivo. Pathog Dis. 70(3):280-288.

Post JC, Preston RA, Aul JJ, Larkins-Pettigrew M, RydquistWhite J, Anderson KW, Wadowsky RM, Reagan DR, Walker ES, Kingsley LA, et al. 1995. Molecular analysis of bacterial pathogens in otitis media with effusion. JAMA J Am Med Assoc. 273(20):1598-1604.

Post JC. 2001. Direct evidence of bacterial biofilms in otitis media. Laryngoscope. 111(12):2083-2094.

Post JC, Aul JJ, White GJ, Wadowsky RM, Zavoral T, Tabari R, Kerber B, Doyle WJ, Ehrlich GD. 1996. PCR-based detection of bacterial DNA after antimicrobial treatment is indicative of persistent, viable bacteria in the chinchilla model of otitis media. Am J Otolaryngol - Head Neck Med Surg. 17: 106-111.

del Prado G, Ruiz V, Naves P, Rodríguez-Cerrato V, Soriano F, del Carmen Ponte M. 2010. Biofilm formation by Streptococcus pneumoniae strains and effects of human serum albumin, ibuprofen, $\mathrm{N}$-acetyl-I-cysteine, amoxicillin, erythromycin, and levofloxacin. Diagn Microbiol Infect Dis. 67(4):311-318

Puig C, Domenech A, Garmendia J, Langereis JD, Mayer P, Calatayud L, Liñares J, Ardanuy C, Marti S. 2014. Increased biofilm formation by nontypeable Haemophilus influenzae isolates from patients with invasive disease or otitis media versus strains recovered from cases of respiratory infections. Appl Environ Microbiol. 80(22):7088-7095.

Qin L, Kida Y, Imamura Y, Kuwano K, Watanabe H. 2013. Impaired capsular polysaccharide is relevant to enhanced biofilm formation and lower virulence in Streptococcus pneumoniae. J Infect Chemother. 19(2):261-271.

Qureishi A, Lee Y, Belfield K, Birchall JP, Daniel M. 2014. Update on otitis media - prevention and treatment. Infect Drug Resist. 7:15-24.

Rayner MG, Zhang Y, Gorry MC, Chen Y, Post JC, Ehrlich GD. 1998. Evidence of bacterial metabolic activity in culturenegative otitis media with effusion. JAMA. 279(4):296-299.

Reid SD, Hong W, Dew KE, Winn DR, Pang B, Watt J, Glover DT, Hollingshead SK, Swords WE. 2009. Streptococcus pneumoniae forms surface-attached communities in the middle ear of experimentally infected chinchillas. J Infect Dis. 199(6):786-794.

Roig-Molina $E$, Domenech $M$, Retamosa $M$ de $G$, NácherVázquez M, Rivas L, Maestro B, García P, García E, Sanz JM. 2019. Widening the antimicrobial spectrum of esters of bicyclic amines: in vitro effect on gram-positive Streptococcus pneumoniae and gram-negative nontypeable 
Haemophilus influenzae biofilms. Biochim Biophys Acta Gen Subj. 1863(1):96-104.

Rosenfeld RM, Shin JJ, Schwartz SR, Coggins R, Gagnon L, Hackell JM, Hoelting D, Hunter LL, Kummer AW, Payne SC, et al. 2016. Clinical practice guideline: otitis media with effusion (update). Otolaryngol Head Neck Surg. 154(1 Suppl):S1-S41.

Rosenfeld RM, Kay D. 2003. Natural history of untreated otitis media. Laryngoscope. 113(10):1645-1657.

Rovers MM, Schilder AG, Zielhuis GA, Rosenfeld RM. 2004. Otitis media. Lancet. 363(9407):465-473.

Schilder AGM, Chonmaitree T, Cripps AW, Rosenfeld RM, Casselbrant ML, Haggard MP, Venekamp RP. 2016. Otitis media. Nat Rev Dis Primers. 2:16063.

Shak JR, Ludewick HP, Howery KE, Sakai F, Yi H, Harvey RM, Paton JC, Klugman KP, Vidal JE. 2013. Novel role for the Streptococcus pneumoniae toxin pneumolysin in the assembly of biofilms. MBio. 4(5):1-10.

Siddiq S, Grainger J. 2015. The diagnosis and management of acute otitis media: American Academy of Pediatrics Guidelines 2013. Arch Dis Child Educ Pract Ed. 100(4): 193-197.

Slinger R, Chan F, Ferris W, Yeung SW, St. Denis M, Gaboury I, Aaron SD. 2006. Multiple combination antibiotic susceptibility testing of nontypeable Haemophilus influenzae biofilms. Diagn Microbiol Infect Dis. 56(3):247-253.

Stol K, Verhaegh SJC, Graamans K, Engel JAM, Sturm PDJ, Melchers WJG, Meis JF, Warris A, Hays JP, Hermans P. 2013. Microbial profiling does not differentiate between childhood recurrent acute otitis media and chronic otitis media with effusion. Int J Pediatr Otorhinolaryngol. 77(4): 488-493.

Stoodley P, Sauer K, Davies DG, Costerton JW. 2002. Biofilms as complex differentiated communities. Annu Rev Microbiol. 56:187-209.

Swords WE, Moore ML, Godzicki L, Bukofzer G, Mitten MJ, Voncannon J. 2004. Sialylation of lipooligosaccharides promotes biofilm formation by nontypeable Haemophilus influenzae. Infect Immun. 72(1):106-113.

Takei S, Hotomi M, Yamanaka N. 2013. Minimal biofilm eradication concentration of antimicrobial agents against nontypeable Haemophilus influenzae isolated from middle ear fluids of intractable acute otitis media. J Infect Chemother. 19(3):504-509.

Talekar SJ, Chochua S, Nelson K, Klugman KP, Quave CL, Vidal JE. 2014. 220D-F2 from Rubus ulmifolius kills Streptococcus pneumoniae planktonic cells and pneumococcal biofilms. PLoS One. 9(5):e97314-30.

Tan A, Li W-S, Verderosa AD, Blakeway LV, Mubaiwa TD, Totsika M, Seib KL. 2019. Moraxella catarrhalis NucM is an entry nuclease involved in extracellular DNA and RNA degradation, cell competence and biofilm scaffolding. Sci Rep. 9(1):2579.

Teele DW, Klein JO, Rosner B. 1989. Epidemiology of otitis media during the first seven years of life in children in greater Boston: a prospective, cohort study. J Infect Dis. 160(1):83-94.

Tikhomirova A, Trappetti C, Paton JC, Kidd SP. 2015. The outcome of $H$. influenzae and $S$. pneumoniae inter-species interactions depends on $\mathrm{pH}$, nutrient availability and growth phase. Int J Med Microbiol. 305(8):881-892.
Trappetti C, Gualdi L, Di Meola L, Jain P, Korir CC, Edmonds P, lannelli F, Ricci S, Pozzi G, Oggioni MR. 2011. The impact of the competence quorum sensing system on Streptococcus pneumoniae biofilms varies depending on the experimental model. BMC Microbiol. 11(1):75.

Trappetti C, Potter AJ, Paton AW, Oggioni MR, Paton JC. 2011. LuxS mediates iron-dependent biofilm formation, competence, and fratricide in Streptococcus pneumoniae. Infect Immun. 79(11):4550-4558.

Ünal CM, Singh B, Fleury $C$, Singh $K$, Chávez de Paz L, Svensäter G, Riesbeck K. 2012. QseC controls biofilm formation of nontypeable Haemophilus influenzae in addition to an Al-2-dependent mechanism. Int J Med Microbiol. 302(6):261-269.

Verhaegh SJ, Streefland A, Dewnarain JK, Farrell DJ, van Belkum A, Hays JP. 2008. Age-related genotypic and phenotypic differences in Moraxella catarrhalis isolates from children and adults presenting with respiratory disease in 2001-2002. Microbiology. 154(4):1178-1184.

Vermee Q, Cohen R, Hays C, Varon E, Bonacorsi S, Bechet S, Thollot F, Corrard F, Poyart C, Levy C, Raymond J. 2019. Biofilm production by Haemophilus influenzae and Streptococcus pneumoniae isolated from the nasopharynx of children with acute otitis media. BMC Infect Dis. 19(1): $1-10$.

Vidal JE, Howery KE, Ludewick HP, Nava P, Klugman KP. 2013. Quorum-sensing systems LuxS/Autoinducer 2 and Com regulate Streptococcus pneumoniae biofilms in a bioreactor with living cultures of human respiratory cells. Infect Immun. 81(4):1341-1353.

Vidal JE, Ludewick HP, Kunkel RM, Zähner D, Klugman KP. 2011. The LuxS-dependent quorum-sensing system regulates early biofilm formation by Streptococcus pneumoniae strain D39. Infect Immun. 79(10):4050-4060.

Wajima T, Anzai Y, Yamada T, Ikoshi H, Noguchi N. 2016. Oldenlandia diffusa extract inhibits biofilm formation by Haemophilus influenzae clinical isolates. PLoS One. 11(11): e0167335-10.

Wang J, Song M, Pan J, Shen X, Liu W, Zhang X, Li H, Deng X. 2018. Quercetin impairs Streptococcus pneumoniae biofilm formation by inhibiting sortase A activity. J Cell Mol Med. 22(12):6228-6237.

Wang W, Reitzer L, Rasko DA, Pearson MM, Blick RJ, Laurence C, Hansen EJ. 2007. Metabolic analysis of Moraxella catarrhalis and the effect of selected in vitro growth conditions on global gene expression. Infect Immun. 75(10):4959-4971.

Webster P, Wu S, Gomez G, Apicella M, Plaut AG, St. Geme JW. 2006. Distribution of bacterial proteins in biofilms formed by nontypeable Haemophilus influenzae. J Histochem Cytochem. 54(7):829-842.

Wei H, Håvarstein LS. 2012. Fratricide is essential for efficient gene transfer between pneumococci in biofilms. Appl Environ Microbiol. 78(16):5897-5905.

Weimer KED, Armbruster CE, Juneau RA, Hong W, Pang B, Swords WE. 2010. Coinfection with Haemophilus influenzae promotes pneumococcal biofilm formation during experimental otitis media and impedes the progression of pneumococcal disease. J Infect Dis. 202(7):1068-1075.

West-Barnette S, Rockel A, Edward W, Swords WE. 2006. Biofilm growth increases phosphorylcholine content and 
decreases potency of nontypeable Haemophilus influenzae endotoxins. Infect Immun. 74(3):1828-1836.

Yadav MK, Go YY, Kim SH, Chae SW, Song JJ. 2017. Antimicrobial and antibiofilm effects of human amniotic/ chorionic membrane extract on Streptococcus pneumoniae. Front Microbiol. 8:1-17.

Yadav MK, Park SW, Chae SW, Song JJ, Kim HC. 2013. Antimicrobial activities of Eugenia caryophyllata extract and its major chemical constituent eugenol against Streptococcus pneumoniae. APMIS. 121(12):1198-1206.
Yadav MK, Vidal JE, Go YY, Kim SH, Chae S-W, Song J-J. 2018. The LuxS/AI-2 Quorum-Sensing system of Streptococcus pneumoniae is required to cause disease, and to regulate virulence- and metabolism-related genes in a rat model of middle ear infection. Front Cell Infect Microbiol. 8:1-16.

Zhang Y, Xu M, Zhang J, Zeng L, Wang Y, Zheng QY. 2014. Risk factors for chronic and recurrent otitis media-A metaanalysis. PLoS One. 9(1):e86397. 